\title{
DIGITALIZATION OF THE WORLD ECONOMY: THEORETICAL AND POLITICAL ASPECTS
}

\author{
Roman Moskalyk', Liana Moskalyk²
}

\begin{abstract}
The purpose of this article is to explore the theoretical background of the digitalization of the world economy, focusing on the channels of influence of digitalization on economic growth. There is also a discussion of policy priorities to enhance the positive effects and limit the negative effects of digitalization. Systematic and comparative analysis methods were used. The main conclusions are that early research on the impact of digital technology on economic growth has failed to fully explain the sustained correlation between digitalization and productivity, mainly because of the limitations of available statistics in the past. Recent studies largely suggest that digital technology can have a positive impact on productivity through channels such as robotics that increase productivity on assembly lines, autonomous machines and intelligent systems that increase data analysis and operations productivity, automated maintenance scheduling that increases productivity by reducing downtime due to breakdowns, 3-D printing technology that increases productivity through rapid production of parts, reducing the supply chain, innovative materials that reduce costs and processing time, informatics that reduce costs and reanalysis time. It is argued that, in reality, these channels may have much less impact on productivity than their potential, due to a number of market characteristics and policy constraints. The phenomenon of the digital divide includes unequal income distribution, unequal access to technology, and risks of increased unemployment, etc. Thus, effective, comprehensive policies to promote digitalization at various levels can have an important impact on the economic and social goals of the nation. Recommendations are given to solve the problem of the "digital divide" as follows: improving skills and technical knowledge, providing high-speed Internet in rural and remote areas, redistribution of labor and capital, competition policy tools in case of a large influence of platform business on markets, reducing financial constraints for young innovative firms and start-ups, transition to public digital services, digital-friendly policy for the elderly population.
\end{abstract}

Key words: digitalization, digital economy, digital technology, economic growth, productivity, policy.

JEL Classification: $\mathrm{O} 33$

\section{Introduction}

Modern trends in the rapid development of digital technologies and their spread to economic life at all levels determine new conditions for solving major economic problems. In addition, the phenomenon of digitalization is accompanied by new configurations, business models, transformation of economic systems, new issues related to access to digital technologies and services, the formation of an appropriate digitalized infrastructure, the need to address issues of cybersecurity, data management and storage, the development of standards for digitalized economies, the rapid development of startups, necessary retraining, consumer protection in the digital world, etc. There are multifaceted problems associated with the digitalization of the economy and the ambiguity of its impact on the development and structure of national economies, the transformation of international trade, the configuration of international economic relations, and so on. Moreover, there is reason to believe that such changes in the global economy are quite uneven,

\footnotetext{
Corresponding author:

${ }^{1}$ Ivan Franko National University of Lviv, Ukraine

E-mail: r_moskalyk@ukr.net

ORCID: $\bar{h}$ ttps://orcid.org/0000-0003-1144-139X

ResearcherID: L-6520-2017

${ }^{2}$ Ivan Franko National University of Lviv, Ukraine

E-mail: liana.moskalyk@gmail.com

ORCID: https://orcid.org/0000-0003-0664-7422
} 
and there are a number of factors that influence the speed of digital transformation of national economies, as well as the impact they cause at different levels and in different sectors of economic life. All of this determines the considerable interest in theoretical and political analysis that reveals the impact of digitalization on the economic growth of individual countries and the world economy.

It is argued that the importance of studying the digitalization of the economy and related concepts is also due to the fact that the proportion of industries that rely on digital technology is constantly increasing. Digital technologies are spreading into various private and public sectors and radically changing the technological structure and the nature of the interrelationships between the elements in those sectors. Some economic activities have already been completely transformed by digital technologies. Platform business, the Internet of Things (IoT), Big Data, and the use of mobile devices have forever changed familiar business models and traditional ideas about how the economy functions. Information and communication technologies (ICT) not only lead to innovative products, but also initiate innovations in business management and public administration.

It can also be argued that a better understanding and effective management of digital transformation is needed because of the many positive and negative effects. Digital technologies have the potential to promote inclusive and sustainable development by fostering innovation, information generation, fast communication, and rational decision-making. The benefits of digitalization, such as creating new places of work, new advanced business models, better healthcare and education, and more opportunities to solve global problems, can also be mentioned. Digital technology can serve as a catalyst for positive change in the economy and lead to economic growth.

On the other hand, digital transformation could have some disruptive effects in the long term. In one scenario, new business models may require less labor and managers, which could lead to higher unemployment. In addition, some people may face unequal access to certain technologies. The age of people can also be an important factor for digital learning. You can also observe the so-called digital divide between countries and generations of people, which can cause certain imbalances in the economy (OECD, 2017).

Given such a vast and ambiguous impact of digitalization on the economy, the goal is to explore the channels of impact of digitalization on the global economy and, on the other hand, to highlight the principles of public policy on digitalization in order to enhance the positive effects and limit the negative consequences of such a rapid phenomenon as digitalization. The main objectives of the study include:

- to outline clearly the definition of digitalization and digital transformation of economic systems, as well as the theoretical links between digitalization, productivity and economic growth;

- to summarize the positive and negative effects of digitalization on national economies;

- to outline public policy strategies to accelerate and enhance the positive effects of digitalization, as well as to overcome the negative effects through an appropriate regulatory environment and digital infrastructure that prevents cybercrime.

This study has attempted to highlight only some of the theoretical and policy issues of the digitalization of the economy. Further research could focus on the significance of the impact of digitalization on economic performance, including a discussion of the correct measurement of digitalization and the choice of econometric estimates.

\section{Theoretical aspects of the impact of digitalization on the global economy}

The term "digital economy" appeared and began to be used in scientific literature in the 1990s. The beginning of the study of the digital economy was associated with the development of the World Wide Web, the emergence of the first commercially successful sites and the beginning of e-commerce. Tapscott D., Negroponte T., Samuelson P., Nalebuff B. were some of the first authors who introduced the term into scientific circulation.

Thomas Mesenbourg identified the following three main components of the concept of "digital economy" (Mesenbourg, 2001):

- supporting infrastructure (hardware, software, telecommunications, networks, etc.);

- e-business (how business is conducted, any processes that an organization conducts through computer networks); 
- e-commerce (the transfer of goods, for example, when a book is sold online).

Currently, there are many scientific attempts to explain and interpret the meaning of the concepts of "digital economy", "digitalization", "digital transformation". Modern scientific experiments are represented by a large number of scientific schools and areas of research. The most notable areas include the impact of the digital economy on the labor market and the structure of the labor force, the correlation between innovation and the digital economy, and the relationship between globalization and digitalization. Some studies have also attempted to explain the impact of digitalization on world GDP, beginning in the late 1980s after the computer sales boom. A new wave of research on the potential of digitalization is related to the spread of $3 \mathrm{G}$ Internet technologies. According to experts of the consulting company PWC, the growth of global GDP between 2000 and 2010 due to the popularization of 3G Internet reached about 45\% (PWC, 2016).

Early studies of the impact of digital technology on economic growth could not fully explain the robust relationship between digitalization and productivity. In 1987 Robert Solow observed, "The computer age can be seen everywhere except in productivity statistics" (Solow, 1987). The productivity paradox describes the slowdown of productivity growth in developed countries in the 1970s and 1980s, despite the rapid growth of information technology. Nevertheless, modern researchers have found some evidence of a link between digital technology and productivity growth. Thanks to improvements in econometric techniques and access to data, the second generation of research has produced results. In particular, D. Jorgenson found positive returns to investment in digital technology (Jorgenson, 2001). Another group of economists focuses on new channels through which digital technology affects economic growth. For example, important links have been identified between investments in digital technologies and human capital, organizational channels, innovation processes, and other knowledge-based assets. Moreover, changes related to information and communication technologies (ICTs) in companies represent a typical process of exploration and experimentation, leading to the success and growth of some and the failure and disappearance of others. Consequently, countries with business environments that allow such processes of so-called creative destruction are more likely to benefit from ICTs, in contrast to countries where such processes are slow or difficult (Pilat, 2005). Some other economists have also concluded that other non-digital sectors have also had positive spillover effects. Digital technology, in particular, can generate excess profits both inside and outside the industry (Brynjolfsson, Hitt, Kim, 2011).

Clearly, the connection between digital technologies can vary significantly across countries. This can be explained by the important position of institutions in determining the effective impact of digital technology on productivity. Stricter regulation of labor and commodity markets reduces incentives to invest in digital technology and other complementary assets. In addition, micro-level findings focusing on individual companies may differ from those at the industry level, where it tends to be a late finding that digital technologies increase productivity and contribute to economic growth. Moreover, the effects in the manufacturing sector may be stronger than in the service sector (PWC, 2016). Conflicting conclusions of different studies may be related to the specifics of performance measurement and samples of firms, industries, or countries. Some country studies have shown that investments in digital technology also improve economic performance. This positive relationship is evidenced by Schreier (2000), Colecchia A., Schreyer P. (2002), Van Ark and others (2002), Daveri (2000), Jorgenson (2003). In contrast, the slowdown in productivity growth in recent decades was found by Gordon (2004) to suggest that digital technology does not affect sustainable economic growth, at least not to the same extent as electricity in the past. Less pessimistic responses can be found in reports from the OECD, which found that the decline in online business start-ups in many OECD countries directly led to a decline in overall productivity growth in those countries (Rivares, Gal, Millot, Sorbe, 2019).

Summarizing recent research, it can be argued that digital technology affects productivity through such channels (Pilat, Nolan, 2016):

- Robots increase productivity on assembly lines, and the list of industries with robotic manufacturing is growing. Robotics can improve logistics and further reduce the price of goods.

- Autonomous cars and smart systems improve productivity with a combination of new sensors 
and mechanisms, big data analytics, cloud services and the Internet of Things.

- Automated maintenance scheduling with advanced sensors, artificial intelligence and machine-to-machine (M2M) communication improves productivity by reducing downtime due to breakdowns.

- 3-D printing technology increases productivity by quickly producing replacement parts, eliminating certain assembly steps and a long supply chain.

- Innovative material science increases productivity by reducing cost and machining time compared to traditional material processing.

- Informatics contributes to productivity by reducing the cost and time of re-analysis.

At the same time, it is assumed that in reality these channels may have much less impact on productivity than their potential. One explanation could be that the latest technologies are mostly found in large enterprises, and small companies cannot afford them. In addition, it can be argued that there is a general inconsistency or limited relevant skills for using the latest technologies, an incomplete understanding of their potential benefits, institutional barriers, certification/ standardization/import tariffs, etc. Some recent studies support the idea of underutilization of technology in many industries (Rivares, Gal, Millot, Sorbe, 2019).

Evidence on the effects of the latest production technologies on labor productivity comes mostly from micro-level studies related to a particular technology in a limited number of countries. The following is a summary of some recent results. Overall, these indicate a significant impact of technology on productivity. However, studies differ in methodological approaches and are often the result of some users' experience of applying these technologies at certain stages, which complicates the process of deriving aggregate results. For example, Brynjolfsson, Hitt, Kim (2011) prove that production volumes and labor productivity are 5-6\% higher in American companies investing in ICTs compared to others. Barua, Mani, Mukherjee (2013) concluded that enhancing data quality and data access by $10 \%$ improves performance by an average of $14 \%$, noting that results may vary slightly by industry. Frey, Osborne et al (2015) found that autonomous mine loaders (mine haulage) can increase production by $10-20 \%$ in some cases, while reducing fuel consumption by $10-15 \%$ and maintenance costs by $8 \%$, and autonomous drilling rigs can increase productivity by $30-60 \%$.

Digital technology can also improve the financial performance of its adherents. Rivares et al (2019) show that by developing the Internet of Things combined with data analytics, a leading U.S. manufacturer saved about $\$ 2$ billion over 5 years (2011-2014 and mostly 2015). Evans, Anninziata (2012) found that improving maintenance efficiency in aviation by $1 \%$ through the use of the Industrial Internet could save commercial airlines about $\$ 2$ billion annually worldwide.

Realizing the benefits of technology often requires the support of appropriate investments in so-called complementary assets, such as the latest skills and qualifications, organizational forms, and the latest business models that are better adapted and bring direct returns to innovators. The combined impact of ICT on productivity is often offset by large differences across firms. For example, in the 2000s, annual labor productivity on the global technology front (advanced firms) increased by an average of $3.5 \%$ in the manufacturing sector, compared to only $0.5 \%$ for non-leading firms. In the service industry, the gap is even larger (OECD, 2017). There are several possible explanations for this disparity in productivity growth among firms. Possible contributing factors are the ability of leading firms to attract the highly skilled workers needed to cope with the rapid pace of innovation. On the other hand, some firms with traditional business approaches still use available resources for unproductive activities. Structural parameters such as limited competition, barriers to entry and exit, and skill mismatches can exacerbate these phenomena. Therefore, maximizing productivity gains from digitalization may require a comprehensive approach that considers all of these elements.

Another part of the research raises the question of whether the slowdown in productivity growth can be caused by the wrong approaches to measurement. Analyzing the existing concepts of measuring GDP as a measure of economic growth or productivity growth, it can be stated that GDP is not an appropriate indicator of productivity. Moskalyk R. and Moskalyk L. (2014) argue that there is a more precise correlation between the channels of international technology diffusion and 
economic growth. And one option is to focus on the total factor productivity indicator as a measure of economic growth when testing the effects of different components of international technology diffusion.

\section{Political aspects of the digitization of the economy}

As noted earlier, digital technology can transform national economies, with enormous potential productivity gains. On the one hand, digitalization creates new opportunities for businesses, workers, and society at large, engaging them in economic activity. However, on the other hand, in the long term, digital transformation can have a destructive impact in some areas, pushing workers out of their usual jobs, creating gaps and unequal opportunities in accessing and using these technologies. Thus, digitalization can increase economic inequality (PWC, 2016). Some studies show that the process of digitalization is uneven over time and across countries. Jorgenson (2001) argues that despite continued digitalization, productivity growth has slowed even in developed countries in recent decades. The slowdown in productivity growth can be attributed to a complex of partially interrelated causes, some of which are related to the global financial crisis and its aftermath (e.g., reduced credit availability affecting investment) and other structural factors such as reduced business dynamics, poor performance of low-performing firms. However, the global economic crisis COVID-19 demonstrated rapid demand for digital technologies and digital-friendly products, but the overall productivity gains from digitalization were not significant enough to offset the overall losses. The OECD (2017) study cites a number of additional factors and policies that may limit the potential for digitalization, as follows:

- digital technologies are highly complementary;

- limited capabilities and assets of firms (technical and managerial skills, organizational capital, innovation and financial capabilities) to adapt digital technology for continuous productivity growth;

- government policies on competition and redistribution of resources and income may affect the incentives of industries and firms to implement digital technologies differently in different countries.

These disadvantages have slowed the spread of digital technologies and reduced the associated productivity gains in developed countries. Profits from digital technologies are not evenly distributed among firms. And those who had better access to key technical, managerial, and organizational skills benefited more than other firms. Successful firms already tended to be more productive, and digital technology has helped strengthen their leadership (OECD, 2019). The nature of some digital activities has led to a small number of high-performing "superstar" firms, with whom other firms are increasingly trying to compete. Even in relatively low-tech industries, the increasing availability of ratings and user reviews online tends to shift demand toward more productive firms. Going forward, advanced technologies such as artificial intelligence require sophisticated skills, large intangible investments that limited actors may be able to afford. Thus, the risk of further inequality only increases.

It can be argued that policy is crucial to promoting effective inclusive digital transformation among a broader range of economic players. OECD (2019) indicates a set of relevant policy priorities: - opportunities to acquire the cognitive, managerial, and technical knowledge and skills needed to achieve the goals of the digital economy; - provision of high-speed Internet by initiating investment in the necessary infrastructure covering rural and remote areas, as well as competitive reforms in the telecommunications segment to reduce prices;

- redistribution of labor and capital between and within firms to reduce administrative barriers to start-up entrepreneurs, and to promote labor mobility and the efficiency of solvency regimes;

- policies related to supporting competition that will ensure a level playing field between different types of service providers (whether platform business or other);

- reducing financial constraints to digitalization by eliminating market failures in financing young, innovative companies and eliminating the equity ownership bias that exists in most tax systems;

- transition to public digital services by expanding the range of public services available online and making government data more transparent to the public.

Such policy priorities should complement each other. In addition, the OECD approach takes into account a broader range of issues related to digitalization, such as taxation, labor, consumer protection, cybersecurity, and more. At the same 
time, non-inclusive digitalization can undermine equal opportunity and widen the income gap, so policymakers need to bridge the so-called "digital divide" and create conditions for less skilled workers and less productive firms to catch up to market leaders. In this sense, one of the most important priorities is professional development (OECD, 2019). We can add that another priority should be included in the policy, namely the development of a special program of digital support for the aged, to help them adapt to the digital reality.

Some other studies make more policy recommendations. For example, Andrews, Nicoletti, Timiliotis (2018) examine digital diffusion through the lens of opportunities and incentives. They assess structural and policy drivers of digital diffusion. According to the authors, both firm capabilities and additional incentives affect the perception and diffusion of digital technologies. Rivares et al (2019) analyze the impact of online platforms on service provider performance. The authors found that online platforms contribute to the productivity of service providers, especially when platform markets are competitive. Gal et al (2019) examine digitalization and productivity at the EU company level. The results of this study show a positive relationship between firms' implementation of digital technology and their productivity. Sorbe et al (2019) examine policies to improve digital productivity. The paper points out that access to high-speed internet, technical and managerial skills, and labor market reforms should help redistribute resources in the economy so that less productive firms are enabled to implement digital technologies.

Another issue for the development of policies to support digitalization is the proper measurement of digitalization. There are some indicators in the following areas: 1) high-tech sector of the economy and its share in total production of goods and services; 2) investment in research and development, software development, education costs and additional retraining; 3 ) production of information and communication equipment; 4) job creation in science and high technology; 5) indicators of cooperation between corporations, venture firms, universities and research organizations; 6) international flows of knowledge, international cooperation in the field of science and innovation; 7) mobility of scientists, engineers, students; 8) dynamics of Internet spread; 9) the share of high-tech products in international trade. Digitalization measures are an important topic that deserves further research.

\section{Conclusions}

This article examines the theoretical premises of the digitalization of the world economy, focusing on the channels of influence of digitalization on economic growth. It also discusses policy priorities for enhancing the positive effects and limiting the negative effects of digitalization. The main conclusions are as follows.

Early research on the impact of digital technology on economic growth could not fully explain the robust correlation between digitalization and productivity, mainly because of the limitations of available statistics in the past. Recent studies largely suggest that digital technology can have a positive impact on productivity through channels such as robotics that increase productivity on assembly lines, autonomous machines and intelligent systems that increase data analysis and productivity of operations, automated maintenance scheduling that increases productivity by reducing downtime due to breakdowns, 3-D printing technology that increases productivity by producing parts quickly, shortening the supply chain, innovative materials that reduce costs and processing time, informatics that reduces costs and reanalysis time.

It can be argued that in reality these channels may have much less impact on productivity than their potential, due to a number of market characteristics and policy constraints. The phenomenon of the "digital divide" includes unequal income distribution, unequal access to technology, risks of increased unemployment, etc. Thus, an effective, comprehensive policy to promote digitalization at various levels can be essential to achieving the nation's economic and social goals.

In conclusion, here are recommendations to address the digital divide: increasing skills and technical knowledge, providing high-speed Internet in rural and remote areas, redistribution of labor and capital, competition policy instruments that support equal rules for all market players and address the huge impact of platform business on markets, reducing financial constraints for young innovative firms and start-ups, transition to public digital services, and digital-friendly policies for the elderly population. 


\section{References:}

Andrews, D., Nicoletti, G., \& Timiliotis, C. (2018). Digital technology diffusion: a matter of capabilities, incentives or both? OECD Economics Department Working Papers. No. 1476. Available at: https://www.oecd-ilibrary.org/economics/digital-technology-diffusion_7c542c16-en

Barua, A., Mani, D., \& Mukherjee, R. (2013). Impacts of effective data on business innovation and growth. Chapter Two of a three-part study, University of Texas at Austin.

Brynjolfsson, E., Hitt, L. M., \& Kim, H. H. (2011). Strength in Numbers: How Does Data-Driven Decision making Affect Firm Performance? Social Science Research Network (SSRN), 22 April. Available at: http://papers.ssrn.com/sol3/papers.cfm?abstract_id=1819486

Colecchia, A., \& Schreyer, P. (2002). The Contribution of Information and Communication Technologies to Economic Growth in Nine OECD Countries. OECD Economic Studies, 1, 153-171. Available at: http://dx.doi.org/10.1787/eco_studies-v2002-art5-en

Daveri, F. (2002). The New Economy in Europe 1992-2001. Discussion Paper No. 70, WIDER, United Nation University.

Evans, P. C., \& Anninziata, M. (2012). Industrial Internet: Pushing the Boundaries of Minds and Machines. General Electrics. Available at: www.ge.com/docs/chapters/Industrial_Internet.pdf

Frey, C. B., Osborne, M., \& others (2015). Citigroup-Oxford Martin School Technology at Work: The Future of Innovation and Employment. Available at: www.oxfordmartin.ox.ac.uk/downloads/ reports/Citi_GPS_Technology_Work.pdf

Gal, P., Nicoletti, G., Renault, T., Sorbe, S., \& Timiliotis, C. (2019). Digitalisation and productivity: In search of the holy grail - Firm-level empirical evidence from EU countries. OECD Economics Department Working Papers No. 1533. Available at: https://www.oecd-ilibrary.org/economics/digitalisation-andproductivity-in-search-of-the-holy-grail-firm-level-empirical-evidence-from-eu-countries_5080f4b6-en Gordon, R. J. (2004). Five puzzles in the Behavior of Productivity, Investment, and Innovation", Working Paper No. w10 660, National Bureau of Economic Research. Available at: www.nber.org/papers/w10660.pdf

Jorgenson, D. W. (2001). IT and the U.S. Economy. American Economic Review, March, vol. 91, no. 1, pp. $1-32$.

Jorgenson, D. W. (2003). Information Technology and the G7 Economies. World Economics, vol. 4, no. 4, pp. 139-169.

Moskalyk, R., \& Moskalyk, L. (2014). Determinants Of Productivity Growth In Developing Countries: What Really Matters? Herald of the Lviv University. Series International Relations, issue 36, part 1, pp. 3-14. Available at: https://intrel.Inu.edu.ua/wp-content/uploads/2015/08/VLNU_Mv_2014_361_3.pdf OECD (2019). Digitalization and Productivity: Story of Complementarities. OECD Economic Outlook, vol. 2019, issue 1. Available at: https://www.oecd.org/economy/growth/digitalisationproductivity-and-inclusiveness/

OECD (2017). Key issues for digital transformation in the G20. Report prepared for a joint G20 German Presidency. OECD conference. Berlin, Germany 12 January 2017. Available at: https://www.oecd.org/g20/key-issues-for-digital-transformation-in-the-g20.pdf

Pilat, D. (2004). The ICT Productivity Paradox: Insights from Micro Data. OECD Economic Studies, vol. no. 1, pp. 37-65. Available at: http://dx.doi.org/10.1787/eco studies-v2004-art3-en

Pilat, D., \& Nolan, A. (2016). Benefiting from the next production revolution / in Patrick Love (ed.), Debate the Issues: New Approaches to Economic Challenges, OECD Publishing, Paris. DOI: http://dx.doi.org/10.1787/9789264264687-22-en

Rivares, A. B., Gal, P., Millot, V., \& Sorbe, S. (2019). Like it or not? The impact of online platforms on the productivity of incumbent service providers. OECD Economics Department Working Papers. 21 May. Available at: https://www.oecd-ilibrary.org/economics/oecd-economics-department-workingpapers_18151973

Schreyer, P. (2000). The Contribution of Information and Communication Technology to Output Growth: A Study of the G7 Countries. OECD Science, Technology and Industry Working Papers, 02, OECD Publishing, Paris. DOI: http://dx.doi.org/10.1787/151634666253

Solow, R. (1987). "We'd better watch out". New York Times Book Review, July 12, p. 36.

Sorbe, S., Gal, P., Nicoletti, G., \& Timiliotis, C. (2019). Digital Dividend: Policies to Harness the Productivity Potential of Digital Technologies. OECD Economic Policy Paper, February, No. 26. Available at: https://www.oecd-ilibrary.org/economics/digital-dividend-policies-to-harness-theproductivity-potential-of-digital-technologies_273176bc-en

Van Ark B. et al. (2002). ICT Investment and Growth Accounts for the European Union, 1980-2000 / / Final Report on ICT and Growth Accounting for the DG Economics and Finance of the European Commission, Brussels, 2002. 